\title{
Hippocampal Excitability Increases during the Estrous Cycle in the Rat: A Potential Role for Brain-Derived Neurotrophic Factor
}

\author{
Helen E. Scharfman, ${ }^{1,2}$ Thomas C. Mercurio, ${ }^{1}$ Jeffrey H. Goodman, ${ }^{1}$ Marlene A. Wilson, ${ }^{4}$ and Neil J. MacLusky ${ }^{3}$ \\ ${ }^{1}$ Center for Neural Recovery and Rehabilitation Research, Helen Hayes Hospital, New York State Department of Health, West Haverstraw, New York 10993- \\ 1195, Departments of ${ }^{2}$ Pharmacology and Neurology and ${ }^{3}$ Obstetrics and Gynecology, Columbia University, New York, New York 10032, and ${ }^{4}$ Department \\ of Pharmacology, Physiology, and Neuroscience, University of South Carolina School of Medicine, Columbia, South Carolina 29208
}

To test the hypothesis that induction of BDNF may contribute to changes in hippocampal excitability occurring during the female reproductive cycle, we examined the distribution of BDNF immunoreactivity and changes in CA1 and CA3 electrophysiology across the estrous cycle in rats. Hippocampal BDNF immunoreactivity increased on the day of proestrus as well as on the following morning (estrus), relative to metestrus or ovariectomized animals. Changes in immunoreactivity were clearest in mossy fiber axons of dentate gyrus granule cells, which contain the highest concentration of BDNF. Increased immunoreactivity was also apparent in the neuropilcontaining dendrites of $\mathrm{CA} 1$ and $\mathrm{CA} 3$ neurons. Electrophysiological recordings in hippocampal slices showed robust cycle-dependent differences. Evoked responses of CA1 neurons to Schaffer collateral stimulation changed over the cycle, with larger maximum responses at both proestrus and estrus relative to metestrus. In area CA3, repetitive hilar stimuli frequently evoked multiple population spikes at proestrus and estrus but only rarely at other cycle stages, and never in slices of ovariectomized rats. Hyperexcitability in area CA3 at proestrus was blocked by exposure to the high-affinity neurotrophin receptor antagonist K252a, or an antagonist of the $\alpha 7$ nicotinic cholinergic receptor, whereas it was induced at metestrus by the addition of BDNF to hippocampal slices.

These studies suggest that hippocampal BDNF levels change across the estrous cycle, accompanied by neurophysiological responses that resemble the effects of BDNF treatment. An estrogen-induced interaction of BDNF and $\alpha 7$ nicotinic receptors on mossy fibers seems responsible for estrous cycle changes in area $\mathrm{CA} 3$. Periovulatory changes in hippocampal function may, thus, involve estrogen-induced increases in BDNF expression.

Key words: cholinergic; epilepsy; estrogen; neurotrophic; nicotinic; mossy fibers; progesterone; testosterone

\section{Introduction}

During the female reproductive cycle, the susceptibility to seizures changes dramatically (Bächstrom, 1976; Sherwood, 1977; Tan and Tan, 2001; for review, see Woolley and Schwartzkroin, 1998), an effect that has been implicated in catamenial epilepsy, in which women exhibit cycle-dependent changes in seizure incidence (Herzog et al., 1997; Rogawski, 2003). The physiological basis of these changes remains poorly understood. Although progesterone and its metabolites have been implicated as anticonvulsants (Belelli et al., 1989; Tauboll and Lindstrom, 1993; Velisek et al., 1999; Frye and Scalise, 2000; Edwards et al., 2001; Frye et al., 2002), it is also clear that the other principal ovarian steroid hormone, estrogen, has powerful excitatory effects that can, under some circumstances, supersede progesterone action (Ed-

Received July 27, 2003; revised Sept. 18, 2003; accepted 0ct. 20, 2003.

This work was supported by National Institutes of Health Grant NS 35762 (H.E.S.) and the Helen Hayes Hospital Foundation. We thank Drs. Lorna Role and David Talmage for discussion, Annmarie Curcio for technical assistance, and Ruth Marshall for administrative support.

Correspondence should be addressed to Dr. Helen Scharfman, Center for Neural Recovery and Rehabilitation Research, Helen Hayes Hospital, Route 9W, West Haverstraw, NY 10993-1195. E-mail: scharfmanh@helenhayeshosp.org.

Copyright $\odot 2003$ Society for Neuroscience $\quad 0270-6474 / 03 / 2311641-12 \$ 15.00 / 0$ wards et al., 1999). The mechanisms underlying the proconvulsant effects of estrogen remain unknown.

Several lines of evidence suggest BDNF as a potential mediator of estrogen action. There is an estrogen-sensitive response element in the BDNF gene, suggesting that estrogen regulates BDNF expression (Sohrabji et al., 1995). Consistent with this hypothesis, ovariectomy decreases BDNF mRNA in the female rat hippocampus, whereas estrogen treatment restores it (Singh et al., 1995; Berchtold et al., 2001). Estrogen treatment has been reported to increase BDNF mRNA in the dentate gyrus and CA3 regions (Pan et al., 1999; Liu et al., 2001; Solum and Handa, 2002). The fact that changes are especially strong in the dentate gyrus/CA3 regions is probably because this is where mossy fiber axons of granule cells are located, and mossy fibers contain relatively high concentrations of BDNF (Conner et al., 1997; Yan et al., 1997).

Many of the effects that have been described for estrogen in the hippocampus resemble responses that have been reported after exposure of the hippocampus to BDNF, including potentiation of synaptic transmission in area CA1. Thus, potentiation occurs in area CA1 after exposure to either BDNF (for review, see Schuman, 1999; Lu and Gottschalk, 2000) or estrogen (Woolley 
et al., 1997; Foy et al., 1999; Sharrow et al., 2002). In addition, dendritic spine changes are induced by BDNF and estrogen (Murphy and Segal, 2001; Danzer et al., 2002).

Although a number of studies have examined effects of estrogen in area CA1, effects in CA3 have not been examined, to date. However, it has been shown that BDNF potentiates mossy fiber transmission in male rats (Scharfman, 1997). In addition, multiple population spikes can be evoked by stimulation of mossy fibers in the presence of BDNF, indicating underlying hyperexcitability (Scharfman, 1997). Mossy fiber stimulation also evoked multiple population spikes in area CA3 of hippocampal slices from transgenic male mice overexpressing BDNF (Croll et al., 1999).

The robust effects of exogenous BDNF in the male hippocampus suggest that estrogen-induced increases in BDNF synthesis in female rats might contribute to the enhanced CNS excitability observed after exposure to estrogen. To test this hypothesis, we examined the distribution of hippocampal BDNF immunoreactivity, as well as changes in CA1 and CA3 excitability, at different stages of the estrous cycle.

\section{Materials and Methods}

Experiments were conducted according to the guidelines set by the $\mathrm{Na}-$ tional Institutes of Health. Experimental procedures were approved by the Institutional Animal Care and Use Committees of the respective institutions (Helen Hayes Hospital/New York State Department of Health, Columbia University, and University of South Carolina School of Medicine). Animals were maintained one to two per cage, with food and water ad libitum, using a $12 \mathrm{hr}$ light/dark cycle (lights on, 7:00 A.M.). All chemicals were purchased from Sigma (St. Louis, MO), unless stated otherwise.

\section{Vaginal cytology and ovariectomy}

Adult female Sprague Dawley rats (Taconic Farms, Germantown, NY) were used for experiments between 2 and 6 months of age. There were six experimental groups, all euthanized between 10:00 A.M. and 12:00 P.M. The first four groups constituted female rats on each day of the regular $4 \mathrm{~d}$ estrous cycle: proestrus, estrus, metestrus (also called diestrus 1), and diestrus 2 (the second day of diestrus). Cycle stage was predicted by vaginal cytology and confirmed by hormone measurement from trunk blood collected at the time of death (see below). Characterization of vaginal cells was based on the description by Turner and Bagnara (1971). Only animals showing at least three consecutive $4 \mathrm{~d}$ estrous cycles were used. Because it became apparent as the experiments progressed that essentially identical patterns of hippocampal electrophysiological activity were observed at metestrus and diestrus 2 , attention was focused primarily on the stages at which different responses were observed (proestrus, estrus, and metestrus) to minimize the number of animals used. The remaining two groups of animals comprised young intact males (48 d old) and ovariectomized females. Ovariectomies were performed via small bilateral dorsal flank incisions, under ketamine (90 $\mathrm{mg} / \mathrm{kg}$ ) and xylazine $(3 \mathrm{mg} / \mathrm{kg})$ anesthesia. Ovariectomized rats were not used until after circulating ovarian steroid levels had declined $(>4 \mathrm{~d})$.

\section{RIA}

RIAs for estradiol and progesterone were conducted at two laboratories independently. The investigators (N.J.M., M.A.W.) conducting the assays were blind to the cycle stage predicted by cytology. Testosterone assays were conducted by a single laboratory, and that investigator was also blinded.

In one laboratory, assays for estradiol and progesterone were performed as described previously (Wilson, 1992). Duplicate serum aliquots of $100 \mu \mathrm{l}$ were extracted twice with $1 \mathrm{ml}$ of ethanol (100\%) by vortexing, followed by centrifugation to promote phase separation. Ethanol extracts were evaporated to dryness in a vacuum concentration (SpeedVac Concentrator; Savant, Holbrook, NY), and residues were resuspended in 200 $\mu \mathrm{l}$ of Calibrator Matriox [Diagnostic Products Corp. (DPC), Los Ange- les, CA]. For estradiol RIA, a DPC double antibody procedure (DPC KE2D1) was used, with standards ranging from 1 to $100 \mathrm{pg} /$ tube. Two hundred microliters of samples or standards were incubated with $100 \mu \mathrm{l}$ of estradiol antiserum for $2 \mathrm{hr}$ at room temperature before the addition of $100 \mu \mathrm{l}^{125} \mathrm{I}$-estradiol. After $1 \mathrm{hr}$ at room temperature, the precipitating solution $(1 \mathrm{ml})$ was added for $10 \mathrm{~min}$ before centrifugation for $15 \mathrm{~min}$ at $1500 \times g$. After aspiration of supernatant, precipitates were counted in a gamma counter.

For analysis of progesterone, $25 \mu \mathrm{l}$ of resuspended sample extract was added to $275 \mu \mathrm{l}$ of $0.1 \mathrm{M}$ sodium phosphate buffer $(0.14 \mathrm{M} \mathrm{NaCl}$ and $0.1 \%$ gelatin, pH 7.0). Samples and standards (5-1000 pg/tube) were incubated with $100 \mu \mathrm{l}$ of antibody diluted to $1: 16,000$ and ${ }^{3} \mathrm{H}-\mathrm{P}$ (NET-381; $103 \mathrm{Ci} / \mathrm{mmol} ; 1.8$ nM; PerkinElmer, Norwalk, CT ). Progesterone antiserum was generously provided by the Reproductive Physiology Program at the University of Illinois. After equilibration at $4^{\circ} \mathrm{C}$ overnight, a suspension of $0.25 \%$ Norit A charcoal and $0.025 \%$ dextran in assay buffer was added. Fifteen minutes later, samples were centrifuged at $1000 \times g$ for $10 \mathrm{~min}\left(4^{\circ} \mathrm{C}\right)$, and the radioactivity in an $800 \mu \mathrm{l}$ aliquot of the supernatant was measured using liquid scintillation spectrophotometric procedures in Ecolite scintillation fluid (ICN Biochemicals, Costa Mesa, CA). Amounts of both estradiol and progesterone in the samples were determined by comparison with the standard curve using log-logit transformation of the data.

The majority of the samples were also assayed for estradiol and progesterone in a second laboratory using Coat-a-Count kits (for estradiol, catalog \#TKE22; for progesterone, catalog \#TKPG1; DPC). In samples assayed in both laboratories, results correlated well (estradiol assay: $r=$ $0.81, F=54.1$, df 1,29, $p<0.0001$; progesterone assay: $r=0.923, F=$ 173.5 , df $1,30, p<0.0001)$. Therefore, data from the two sets of procedures are combined for presentation. Testosterone was also assayed in the majority of samples using a Coat-a-Count kit (catalog \#TKTT1; DPC).

RIA analysis was conducted in most of the animals studied for electrophysiology. The assays in ovariectomized females confirmed the expected loss of circulating estradiol and progesterone. In males, testosterone levels were within the normal expected range $(1-3 \mathrm{ng} / \mathrm{ml})$, whereas estradiol levels were at the limit of detection of the assay. Ten of 15 cycling females were assayed for both estradiol and progesterone: the five exceptions were a subset of the 43 cycling females used for CA3 electrophysiology (two at proestrus and three at metestrus), in which problems with either the serum collection or the RIAs themselves precluded reliable measurement of estradiol or progesterone. The data from these five animals were included in the electrophysiological analysis in relation to the stage of the cycle (see below), because in the remaining 38 rats, the measured serum estradiol and progesterone levels were always concordant with the cycle stage predicted from vaginal cytology.

\section{Immmunocytochemistry}

For immunocytochemistry, animals were perfusion fixed (4\% paraformaldehyde, $\mathrm{pH} 7.4$ ) after deep anesthesia with urethane ( $3 \mathrm{gm} / \mathrm{kg}$, i.p). For measurements of circulating hormone levels, blood was withdrawn from the heart by cardiac puncture immediately before perfusion. Brains were left in situ and refrigerated overnight. On the following day, brains were removed and transferred to $30 \%$ sucrose in $0.1 \mathrm{~m}$ phosphate buffer until they sank and were cut with a cryostat $(40 \mu \mathrm{m})$.

Sections were first washed in $0.05 \mathrm{M}$ potassium PBS (KPBS) and then treated with $0.5 \% \mathrm{H}_{2} \mathrm{O}_{2}$ in $\mathrm{KPBS}$ for $30 \mathrm{~min}$. After a 5 min wash in KPBS, sections were incubated in $10 \%$ normal goat serum, $1 \% \mathrm{BSA}$, and $0.4 \%$ Triton X-100 in KPBS for $20 \mathrm{~min}$. Sections were incubated in antisera (polyclonal; 1:30,000; kindly provided by Amgen-Regeneron Partners, Tarrytown, NY) in $1 \%$ BSA and $0.4 \%$ Triton X-100 in KPBS overnight at $4{ }^{\circ} \mathrm{C}$ and subsequently rinsed 10 times (10 min each) in $0.25 \%$ BSA and $0.02 \%$ Triton X-100 in 0.01 м KPBS. Then, sections were incubated in a biotinylated goat anti-rabbit $\operatorname{IgG}$ secondary antibody (1:1,000; Vector Laboratories, Burlingame, CA) in 1\% BSA and $0.02 \%$ Triton X-100 in KPBS for $1 \mathrm{hr}$, followed by ABC (ABC Elite kit; 1:1,000; Vector Laboratories) in 1\% BSA in KPBS for $1 \mathrm{hr}$. Sections were rinsed in KPBS and then Tris buffer and reacted with DAB $(50 \mathrm{mg} / 100 \mathrm{ml}$ in $0.1 \mathrm{M}$ Tris; 
Polysciences, Warrington, $\mathrm{PA}$ ) in $50 \mathrm{mM} \mathrm{NiCl}_{2}$ and then washed (three times for $5 \mathrm{~min}$ ) in Tris.

\section{Hippocampal slice electrophysiology}

Slice preparation. Care was taken to minimize stress to the animal, because stress is known to elevate corticosteroids, which could affect hippocampus in a variety of ways, and both stress and corticosteroids influence BDNF (Schaaf et al., 1998; Rage et al., 2002). Thus, the same person who conducted vaginal lavage also anesthetized the animals. Other persons were not present. Each animal was handled as it had been in the past weeks, as if another cytological examination was about to be conducted, but the animal was transferred quickly to a container for $\mathrm{CO}_{2}$ anesthesia instead. Animals were decapitated within $2 \mathrm{~min}$ of exposure to $\mathrm{CO}_{2}$.

After anesthesia and decapitation, one hemisphere was immediately immersed in ice-cold artificial CSF (ACSF) containing sucrose instead of $\mathrm{NaCl}$ (in mm: 126 sucrose, $5.0 \mathrm{KCl}, 2.0 \mathrm{CaCl}_{2}, 2.0 \mathrm{MgSO}_{4}, 1.25$ $\mathrm{NaH}_{2} \mathrm{PO} 4,26.0 \mathrm{NaHCO}_{3}$, and 10.0 D-glucose, $\mathrm{pH}$ 7.4). After trimming from the dorsal cortex with a razor blade so that it formed a flat surface, the dorsal surface was glued to a Teflon holding tray with cyanoacrylate and sliced horizontally ( $400 \mu \mathrm{m}$ thick) with a Vibroslice (Stoelting Instruments, Wood Dale, IL). Sections were immediately trimmed with fine scissors, while still immersed in buffer, so that they contained the hippocampus and overlying cortex only. Slices were transferred in sucrose buffer with a wide-bore pasteur pipette to oxygenated $\left(95 \% \mathrm{O}_{2} / 5 \%\right.$ $\mathrm{CO}_{2}$ ) ACSF at room temperature and transferred, after all slices were cut, to a recording chamber (modified from the one sold by Fine Science Tools, Foster City, CA) (Scharfman et al., 2001). Slices were submerged, except for their upper surface in warm $\left(31-32^{\circ} \mathrm{C}\right)$, oxygenated $\left(95 \% \mathrm{O}_{2} /\right.$ $5 \% \mathrm{CO}_{2}$ ) ACSF. After $30 \mathrm{~min}$, the ACSF was switched to one that contained $\mathrm{NaCl}$, substituted equimolar for sucrose. Recordings began 30 min later and continued for up to $5 \mathrm{hr}$. Flow rate was $\sim 1 \mathrm{ml} / \mathrm{min}$.

For each experiment, approximately six slices from the mid or ventral hippocampus were placed into the recording chamber and were sequentially evaluated after $1 \mathrm{hr}$ to assess viability. Only those slices that passed the criteria for viability (see below) are included in Results.

Recording and stimulation. Extracellular recording electrodes were made from borosilicate capillary-filled glass (inner diameter, $0.6 \mathrm{~mm}$; outer diameter, $1.0 \mathrm{~mm}$; World Precision Instruments, Sarasota, FL) that were pulled horizontally (Flaming-Brown P97; Sutter Instruments, Novato, CA) and filled with ACSF (resistance, 5-10 M 2 ). For stimulation of afferents, a monopolar-stimulating electrode made from Teflon-coated stainless steel wire (75 $\mu \mathrm{m}$ diameter; A \& M Systems, Carlsborg, WA) was used. Current pulses (100 $\mu \mathrm{A}, 10-200 \mu \mathrm{sec})$ were triggered digitally using an interval generator (Pulsemaster; World Precision Instruments) and stimulus isolator (AMPI Instruments, Jerusalem, Israel). Signals were amplified (Axoclamp 2B; Axon Instruments, Union City, CA), recorded digitally (Pro 10 oscilloscope; Nicolet Instruments, Madison, WI), and analyzed offline using Nicolet software and Origin 7.0 (OriginLab, Northampton, MA).

Stimulation and recording sites are shown in Figures 3 and 4. In all experiments, the recording electrodes were placed at the depth in the slice that produced a maximal response. The stimulating electrodes were placed so that they just touched the upper surface of the slice. For area CA3 recordings, the hilar-stimulating electrode was positioned slightly ventral to the midway point between the end of the CA3c pyramidal cell layer and the granule cell layer, close to the crest of the dentate gyrus. Stimulation of the fimbria was made at the ventral part of the white matter of the fimbria as it joins the hippocamus, near stratum oriens of CA3b. The Schaffer collaterals were stimulated at the border of CA1 and CA2, $\sim 200 \mu \mathrm{m}$ from the pyramidal cell layer. This position was near the end of the white fiber bundle of the Schaffer collaterals, which was visualized by transillumination of the slice. Recording sites were in area CA3b or at the border of CA3b and CA3c. For area CA1 recordings, the stimulation site was the same as the Schaffer collateral site used for recordings in area CA3. The recording electrode was in CA1b, on the border of the pyramidal cell layer and stratum oriens. Care was taken to record and stimulate in analogous areas of different slices to minimize interslice differences.

At the onset of each experiment, slices were screened to determine which were viable. Slices that were accepted for study had a population spike that was at least $5 \mathrm{mV}$ to afferent stimulation. These criteria are based on the close association of numerous, healthy intracellularly recorded pyramidal neurons with slices that demonstrated such field potentials, and the lack thereof in slices with lesser field potentials.

Pharmacology. D-APV was dissolved in $0.9 \% \mathrm{NaCl}$ and stored as a 10 mu stock solution at $-20^{\circ} \mathrm{C}$ until the day of use, when it was thawed and diluted in ACSF to reach the final concentration. Methyllycaconitine (MLA) was also dissolved in $0.9 \% \mathrm{NaCl}$, stored as a $10 \mathrm{~mm}$ stock solution at $4^{\circ} \mathrm{C}$ until the day of use, diluted in ACSF to $1 \mathrm{~mm}$, and then diluted to the final concentration. K252a (Calbiochem, San Diego, CA) was dissolved in DMSO, so that the final concentration of DMSO in buffer was $0.05 \%$. This concentration was chosen because $0.08 \%$, but not $0.05 \%$, led to an increase in population spike amplitude in area CA3 in response to mossy fiber stimulation in control experiments $(0.05 \%, n=3 ; 0.08 \%$, $n=3$ ). K252a was added directly to the buffer to reach its final concentration. BDNF was provided by Amgen-Regeneron Partners. It was diluted to $100 \mu \mathrm{g} / \mathrm{ml}$ in $0.05 \% \mathrm{BSA}$ and stored at $4^{\circ} \mathrm{C}$ until the day of use, when it was diluted in buffer to reach the final concentration (100 ng/ $\mathrm{ml}$ ). Sterile pipette tips and Eppendorf tubes that were prerinsed in $0.05 \%$ BSA were used for dilution.

\section{Data analysis}

Electrophysiology. In area CA1, population spike amplitude was defined as the average of the negative and positive voltage deflections that comprise the population spike. The maximal population spike was measured from the largest response that could be elicited. This was defined by increasing stimulus strength in steps of $10-20 \mu$ sec using a $100 \mu \mathrm{A}$ rectangular stimulus. The maximal stimulus was defined as the stimulus that elicited a response that differed by $<10 \%$ in amplitude from the population spike produced by a stimulus that was $10-20 \mu$ sec shorter. Typically, stimuli were tested between 10 and $200 \mu \mathrm{sec}$. All stimuli were 100 $\mu \mathrm{A}$ in amplitude.

In area CA3, hyperexcitability was defined as more than one population spike per stimulus. For the purposes of this study, additional population spikes were included only if they were $>2 \mathrm{mV}$ in amplitude. This criterion was used because in normal male rat slices there can be small undulations and unit activity in the CA3 cell layer that can appear to be a $1 \mathrm{mV}$ spike-like event. To ensure that these events would not be included, an amplitude criterion well above $1 \mathrm{mV}$ was chosen.

Statistics. Programs used for statistical analysis included Microsoft Excel 2000 (Microsoft, Redmond, WA) and Statview (SAS Institute, Cary, NC). $t$ tests assumed unequal variance and were two tailed. $\chi^{2}$ analysis was used to compare incidence of hyperexcitability at different stages of the cycle. Hormone levels across the estrous cycle were compared by one-way ANOVA, followed by the Scheffe's post hoc test. The potential relationship between hormone levels and the incidence of multiple population spikes in the slices was examined using stepwise partial linear regression. Means are reported $\pm \mathrm{SEM}$. The criterion for statistical significance was set at $p<0.05$.

Data relating CA1 population spike amplitude to different stimulus durations were analyzed by computer-assisted nonlinear least squares curve fitting, essentially as described by DeLean et al. (1978), using the programs developed by these authors. The individual curves describing the relationship between output spike amplitude $(y)$ and stimulus duration $(x)$ at each of the stages of the cycle were fitted to a sigmoidal four-parameter logistic function $y=D+\left[A-D /\left(1+(x / C)^{\mathrm{B}}\right)\right]$, where $A$ and $D$ are the expected maximum and minimum responses, respectively, $B$ is a slope factor, and $C$ is the stimulus duration expected to generate a half-maximal response (abbreviated for purposes of this study as $\mathrm{ES}_{50}$ ). Because $\mathrm{CA} 1$ population spikes were never observed at stimulus durations below $20 \mu \mathrm{sec}$, the expected minimum response was zero in all cases. Constrained curve fitting and analysis of residual variance were used to test the significance of differences between the calculated maximal response and $\mathrm{ES}_{50}$ values on each day of the cycle (DeLean et al., 1978). 


\section{Results}

\section{Variation in BDNF expression during} the estrous cycle

Thirty animals were used for BDNF immunocytochemistry, including animals killed on the morning of proestrus $(n=$ $7)$, estrus $(n=10)$, metestrus $(n=8)$, after ovariectomy $(n=3)$, and intact adult males $(n=2)$. Figure 1 compares sections from each of these experimental groups that were processed concurrently. The comparison shows several differences in BDNF immunoreactivity. First, cycling rats had stronger immunoreactivity than ovariectomized or male rats. Second, mossy fiber BDNF was greater at proestrus and estrus than at metestrus. Third, the neuropil surrounding the pyramidal cell layers (i.e., stratum radiatum of area CA1 and CA3) demonstrated increased immunoreactivity at proestrus and estrus.

In all of our immunocytochemical comparisons, tissue sections were processed concurrently. Because of the large amount of tissue to be processed, the animals were divided into test groups containing at least one animal at each cycle stage. Two of the groups also included sections from ovariectomized rats and males. For all evaluations, the same septotemporal level of the dorsal hippocampus was used, $\sim 3.00-4.00 \mathrm{~mm}$ posterior to bregma (Paxinos and Watson, 1986). Evaluations were conducted by an investigator who was blinded to the hormonal state of the animal, and focused on the mossy fiber pathway. In the test groups that included all cycle stages as well as ovariectomized and male rats, cycling animals always demonstrated greater BDNF immunoreactivity in mossy fibers (Fig. 1). In the other test groups, mossy fiber immunoreactivity was greater at proestrus and estrus relative to metestrus in 13 of 19 animals.

The six cycling females that did not fit the patterns of BDNF immunostaining included two proestrous animals that had low mossy fiber immunoreactivity and four metestrous animals with immunoreactivity that was unusually high, similar to the immunoreactivity of the estrous rats. RIA of trunk blood collected at the time of death showed that the two proestrous animals had levels of estradiol commensurate with the predicted cycle stage. However, there was a slightly elevated testosterone level in one of these animals (171 $\mathrm{pg} / \mathrm{ml}$; other females had testosterone $<70 \mathrm{pg} / \mathrm{ml}$ ).

Figure 2 shows sections from the hippocampi of animals killed on the mornings of proestrus (Fig. 2A), estrus (Fig. 2B), or metestrus (Fig. 2C). An interesting difference among experimental groups is the darker immunoreactivity in the granule cell layer of the proestrous rat. This was evident in four of seven proestrous rats; in the three exceptions, differences in granule cell immunoreactivity were not distinguishable relative to other cycle stages. At higher magnification (Fig. 2A2), immunoreactivity was ap- parent in the granule cell layer at proestrus as thin rims or "halos" of cytoplasm around the large, nonimmunoreactive nuclei of granule cells. This may reflect BDNF synthesis in granule cells shortly after induction by rising estrogen levels. In addition, hilar BDNF immunoreactivity, reflecting primarily axonal BDNF, is lighter at proestrus relative to estrus. Taken together, this pattern of expression suggests that BDNF is synthesized in granule cell somata at proestrus preferentially and subsequently transported to axons in the hilus at estrus. This is consistent with evidence that mossy fiber BDNF is transported anterogradely (Conner et al., 1997). Figure $2 D$ shows that a few CA3 pyramidal cell somata were intensely BDNF immunoreactive at proestrus. Such clusters were evident throughout the CA3 pyramidal cell layer.

\section{Slice electrophysiology}

For area CA1 electrophysiology experiments, 14 animals were used (proestrus, $n=5$; estrus, $n=4$; metestrus, $n=5$ ). For area CA3, 57 animals were used (proestrus, $n=16$; estrus, $n=11$, metestrus, $n=13$; diestrus $2, n=3$; ovariectomy, $n=14$ ). All 

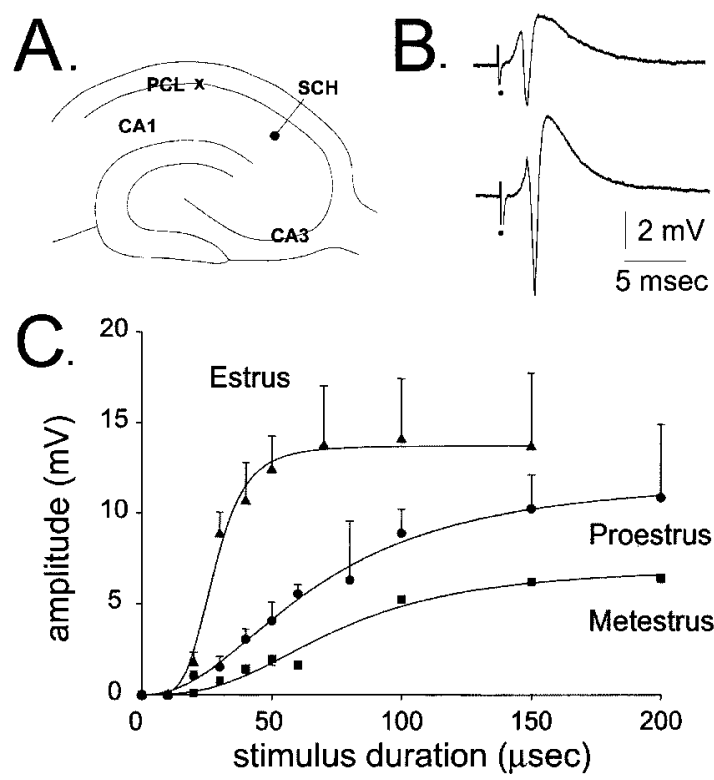

Figure 3. Changes in evoked responses of area CA1 pyramidal cells during the estrous cycle. A, Diagram of the Schaffer collaterals stimulating site $(\mathrm{SCH})$ and recording site in the $\mathrm{CA} 1 \mathrm{~b}$ pyramidal cell layer $(\mathrm{x})$. $B$, Representative evoked responses to half-maximal stimulus at metestrus (top) and estrus (bottom). For this figure and others, stimulus artifacts are marked by dots and are truncated. C, Population spike amplitude is plotted as a function of stimulus intensity. The stimulus was a rectangular $100 \mu \mathrm{A}$ pulse, and stimulus intensity was adjusted by changing stimulus duration in $10 \mu \mathrm{sec}$ intervals. Fourteen animals were studied (proestrus, $n=5$; estrus, $n=4$; metestrus, $n=5$ ). Two to four slices per animal were used, and results for all slices of a given animal were averaged. Results were then averaged across animals. Data represent means $\pm S E M$ of the results for each stimulus duration, at each stage of the cycle. The lines drawn through the points represent the best-fit curves generated by computer-assisted least-squares analysis (see Materials and Methods).

animals were killed between 10:00 A.M. and 12:00 P.M. In many of the experiments in which one subfield was examined, another subfield in the same slice was often evaluated subsequently. The order was randomized so that any effects of stimulation in one subfield on results from another subfield would be minimized. In fact, there was no indication of such effects at any point in the experiments.

\section{Area CA1}

Differences were observed between different stages of the cycle in the CA1 response to a single stimulus delivered via Schaffer collateral stimulation. For these experiments, a total of 34 slices were tested (proestrus, $n=17$; estrus, $n=9$; metestrus $n=8$ ). Figure $3 A$ demonstrates the sites in area CA1 that were used for recording and stimulation, and Figure $3 B$ shows a representative example of half-maximal responses evoked at estrus and metestrus. Figure $3 C$ shows the input-output functions for area CA1 of slices from rats at proestrus, estrus, and metestrus. These curves were based on responses evoked by single stimuli that were 100 $\mu \mathrm{A}$ in amplitude and $10-200 \mu \mathrm{sec}$ in duration. The input-output functions were fitted using a four-parameter logistic formula (DeLean et al., 1978) (see Materials and Methods). At all three cycle stages, a stimulus duration of at least $20 \mu \mathrm{sec}$ was required before a population spike was observed at the recording electrode. As the stimulus duration increased, the magnitude of the population spike also increased, but the relationship between stimulus duration and CA1 population spike amplitude depended on the cycle stage (Fig. 3C; Table 1). At proestrus and metestrus, the shape of the relationship was similar. Statistical analysis revealed no significant difference between the stimulus
Table 1. Changes in the area CA1 input- output function during the estrous cycle

\begin{tabular}{lll}
\hline Cycle stage & $\begin{array}{l}\text { Maximum population } \\
\text { spike amplitude }(\mathrm{mV})\end{array}$ & $\mathrm{ES}_{50}(\mu \mathrm{sec})$ \\
\hline Proestrus $(n=17$ slices $)$ & $12.0 \pm 0.9^{*}$ & $67.8 \pm 6.7$ \\
Estrus $(n=8)$ & $13.7 \pm 0.3^{*}$ & $28.8 \pm 0.8^{* *}$ \\
Metestrus $(n=9)$ & $7.03 \pm 0.81$ & $75.1 \pm 10.9$ \\
\hline
\end{tabular}

The data in Figure 3 were subjected to nonlinear least-squares curve-fitting analysis, relating the CA1 population spike amplitude to the duration of the input stimulus using a four-parameter logistic function (see Materials and Methods). For each stage of the cycle, estimates were determined for the maximal population spike amplitude and the $\mathrm{ES}_{50}$ value (stimulus duration required to obtain a $50 \%$ maximal CA1 spike). Data are presented as the 'best fit' parameter estimates, together with their associated variances (expressed as SE of the mean) calculated from the regression analysis (DeLean et al, 1978). Statistical analysis, based on analysis of residual variance: ${ }^{*} p<0.0001$ compared with data in slices from animals at metestrus; ${ }^{* *} p<0.0001$ compared with data in slices from animals at proestrus and metestrus.

durations required to elicit a half maximal response $\left(\mathrm{ES}_{50}\right)$ at proestrus and metestrus $(p=0.516)$ : at both stages, this value was $\sim 70 \mu$ sec (Table 1 ). However, mean responses at all stimulus durations tended to be larger and more variable at proestrus (Fig. $3 C$ ). Nonlinear curve fit analysis revealed an increase of almost twofold in the maximal response observed at proestrus compared with that at metestrus $(F=44.6$; df 1,$21 ; p<0.0001)$.

Estimates of maximal CA1 response amplitude at proestrus and estrus were not significantly different $(F=2.12$; df 1,$19 ; p=$ 0.163) (Table 1). However, the shape of the CA1 stimulusresponse relationship was markedly different at these two stages (Fig. 3C). Constrained curve fitting analysis (see Materials and Methods) revealed that this was the result of a more than twofold reduction between proestrus and estrus in the $\mathrm{ES}_{50}$ values $(F=$ 167.7; df 1,20; $p<0.0001$ ) (Table 1).

\section{Area $C A 3$}

There were striking differences in the effects of afferent stimulation in area CA3 during the estrous cycle. During initial experiments, we noticed that single hilar stimuli at low frequency $(0.05$ $\mathrm{Hz}$ ) could lead to multiple CA3 population spikes at proestrus and estrus, and sometimes this led to spreading depression. Therefore, detailed input-output functions like those in CA1 were not obtained because many stimuli, particularly near the maximal stimulus duration, would be likely to evoke spreading depression in CA3. Although spreading depression seems to last only minutes, there could have been lasting effects on aspects of slice physiology. Thus, in CA3, the end point chosen was the ability of paired hilar stimuli to evoke multiple population spikes. The stimulus strength was set at half-maximal, and only five pairs

Table 2. Hyperexcitability in area CA3 of female rat hippocampal slices

\begin{tabular}{|c|c|c|c|}
\hline & \multicolumn{3}{|c|}{ Measure of hyperexcitability } \\
\hline & $\begin{array}{l}\text { Total number of } \\
\text { hyperexcitable } \\
\text { slices }^{a}(\%)\end{array}$ & $\begin{array}{l}\text { Total number of } \\
\text { animals with } \\
\text { more than one } \\
\text { hyperexcitable } \\
\text { slice }^{b}(\%)\end{array}$ & $\begin{array}{l}\text { Percentage of } \\
\text { hyperexcitable slices } \\
\text { per animal }^{c}(n)\end{array}$ \\
\hline Proestrus & $18 / 65$ (27.6) & $9 / 16(56.2)$ & $31.6 \pm 7.8(16)$ \\
\hline Estrus & 24/42 (80.9) & 10/11 (90.9) & $55.4 \pm 9.3(11)$ \\
\hline Metestrus & $5 / 60(8.3)$ & $3 / 13(23.1)$ & $7.1 \pm 4.2(13)$ \\
\hline Diestrus 2 & $1 / 12(8.3)$ & $1 / 3(33.3)$ & $6.7 \pm 6.7(3)$ \\
\hline Ovariectomy & $0 / 50(0)$ & $0 / 14(0)$ & 0 \\
\hline
\end{tabular}

$\overline{\text { Three measures of hyperexcitability were used. For all measures, hyperexcitability was defined as more than one } \mathrm{CA} 3}$ population spike per stimulus after five pairs of half-maximal hilar stimuli at $1 \mathrm{~Hz}$.

${ }^{a}$ The number of slices that exhibited hyperexcitability as a proportion of the total number of slices tested. From two to six slices were tested per animal.

${ }^{b}$ The number of animals that had at least one slice that exhibited hyperexcitability. As above, two to six slices were evaluated per animal. All slices were placed in the recording chamber immediately after slice preparation and remained there for the entire experiment, so they would be exposed to the same conditions.

'The number of slices demonstrating hyperexcitability was divided by the total number of slices tested for that animal. The means \pm SEM for all animals and the numbers of animals $(n)$ are shown. 
of stimuli (40 msec interstimulus interval) were triggered (consecutively, at $1 \mathrm{~Hz}$ ). This paradigm was also adopted because it has been useful in previous experiments to discriminate slices with altered excitability (Scharfman, 1997; Croll et al., 1999).

In proestrous and estrous rats, two to five pairs of stimuli at $1 \mathrm{~Hz}$ frequently evoked more than one CA3 population spike per stimulus (Table 2). We refer to this as "hyperexcitability." Unlike proestrous or estrous slices, hyperexcitability was rare in slices from metestrous rats and never occurred in slices from ovariectomized rats (Table 2). Representative examples are shown in Figure 4. In all cases, the first stimulus pair evoked a single population spike in CA3 immediately after each stimulus. Thereafter, additional, longer latency population spikes often occurred after the second to fifth pair of stimuli. When hyperexcitability occurred, the maximum number of additional population spikes recruited by the fifth pair of stimuli were (mean \pm SEM): $2.3 \pm 0.28$ for proestrus $(n=18$ slices from 9 rats), $2.1 \pm 0.25$ for estrus $(n=21$ slices from 11 rats), and $1.5 \pm 0.50$ for metestrus ( $n=4$ slices from 3 rats), which were not statistically different (ANOVA; $F=0.89 ; p=0.418)$. In these slices, the number of paired stimuli that were required to elicit the maximum number of population spikes were $4.3 \pm 0.18$ for proestrus, $4.4 \pm 0.20$ for estrus, and $4.5 \pm 0.29$ for metestrus, which were not significantly different (ANOVA; $F=0.067 ; p=$ 0.937).

If stimulation continued, many more population spikes were recruited (as many as 10 per stimulus after 10 paired stimuli at 1 $\mathrm{Hz}$; longer; $>10$ pairs of consecutive stimuli were never tested), and they became larger in amplitude with shorter interspike intervals (Fig. 4). However, spontaneous population spikes in CA3 were never detected. Slices from three rats killed on the morning of diestrus 2 ( $24 \mathrm{hr}$ after metestrus and $24 \mathrm{hr}$ before proestrus) were similar to metestrous rats (Table 2). In contrast to area CA3, area CA1 showed no hyperexcitability (i.e., multiple population spikes) when the same stimulus paradigm used in CA3 was tested in area CA1 with Schaffer collateral stimulation $(n=22$ slices from proestrous and estrous rats).

Mossy fiber specificity. Only hilar-evoked responses in area CA3 were able to discriminate between cycle stages and ovariectomized rats. Thus, multiple population spikes were not evoked in area CA3 when paired stimuli (interstimulus interval, $40 \mathrm{msec}$ ) at $1 \mathrm{~Hz}$ were applied to the Schaffer collaterals or fimbria. Thus, more than one population spike per stimulus was never observed ( $n=4$ slices from two proestrous rats; $n=6$ slices from two estrous rats) (Fig. 5). Even when more than five pairs of stimuli were triggered at $1 \mathrm{~Hz}$, and stimulus strength was increased from half-maximum to maximum, fimbria and Schaffer collateral stimulation only evoked one CA3 population spike per stimulus ( $n=4$ slices from two proestrous rats; $n=6$ slices from two estrous rats) (Fig. 5). Yet, in each of these slices, using the same recording position (in the CA3 pyramidal cell layer), multiple

\section{A. Mossy fiber stimulation}

\section{B. Fimbria stimulation}
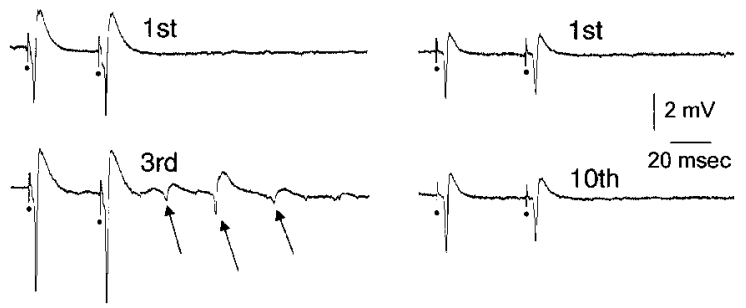

Figure 5. Afferent specificity of area CA3 hyperexcitability. A, Recordings in the area CA3b pyramidal cell layer to the first and third pair of stimuli triggered 1 sec apart. The interstimulus interval between each pair was $40 \mathrm{msec}$. The slice was from an animal killed on the morning of estrus. $B$, Same recording site as $A$, but stimuli were triggered by fimbria stimulation and continued longer than $A$ (for $10 \mathrm{sec}$ ). The responses to the 1st and 10th pairs of stimuli are shown. Unlike in $A$, multiple population spikes ( $A$, arrows) did not occur in response to fimbria stimulation.

population spikes were evoked after moving the stimulating electrode to the hilus and triggering two to five pairs of half-maximal stimuli (Fig. 5).

Comparison of responses in area CA3 to fimbria and Schaffer collateral stimulation versus hilar stimulation suggested that the effects observed at proestrus and estrus were evoked preferentially by mossy fiber stimulation, suggesting a presynaptic mechanism. However, a hilar stimulus can activate other pathways besides the mossy fibers (Claiborne et al., 1993). To further probe the role of mossy fibers in the generation of multiple population spikes, simultaneous recordings were made in several strata of 


\section{A. Laminar profile single stimulus}

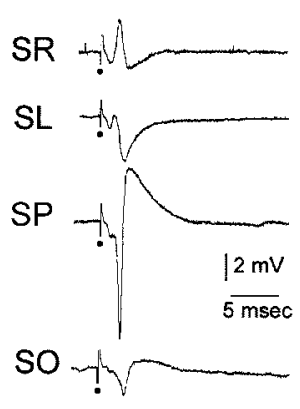

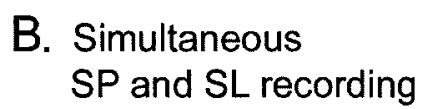
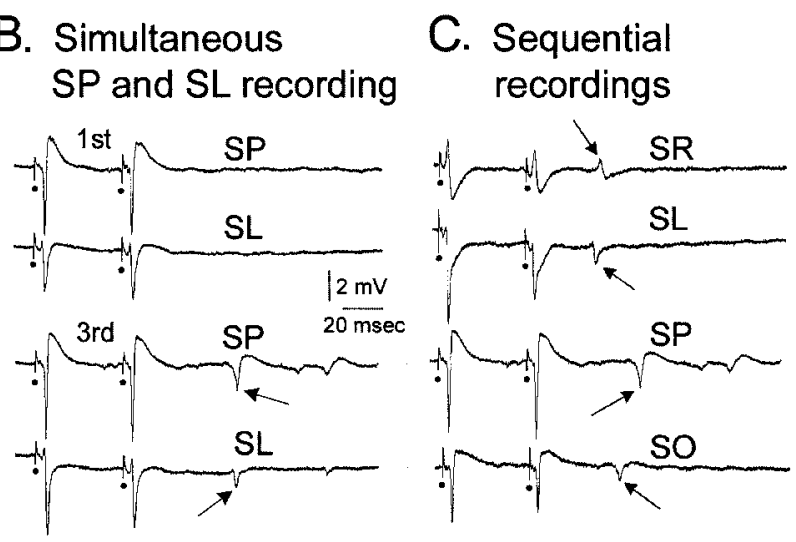

Figure 6. Laminar specificity of area CA3 hyperexcitability at proestrus and estrus. A, Responses to the same hilar stimulus were recorded consecutively by moving the recording electrode to different strata of area $C A 3 b$. Recordings were from a proestrous rat and sites were positioned as shown by the $\mathrm{x}$ in Figure $4 A$. B, Simultaneous recordings from stratum pyramidale (SP) and stratum lucidum (SL) of CA3b in a slice from an estrous rat. The top two traces are the first pair of responses to hilar stimuli, recorded simultaneously in SP and SL. The bottom two traces are the responses to the third pair of stimuli. Pairs were triggered at $1 \mathrm{~Hz}$. Arrows point to a spontaneous population spike and field EPSP. C, Sequential recordings in the same slice, using the same hilar stimuli. Only the third response of a train of three pairs of stimuli (each pair triggered 1 sec apart) is shown. SR, Recording in stratum radiatum; $\mathrm{SL}$, subsequent recording in stratum lucidum; $\mathrm{SP}$, subsequent recording in stratum pyramidale; $\mathrm{SO}$, subsequent recording in stratum oriens. The largest field EPSP evoked by a stimulus, as well as the largest field EPSP recorded spontaneously, were always recorded in stratum lucidum, the layer corresponding to the mossy fibers. Note that the events occurring long after the pair of stimuli (arrows), indicative of hyperexcitability, had variable latencies. This was a characteristic of other experiments also.

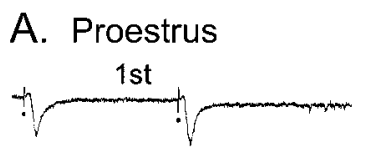

B. Proestrus + APV
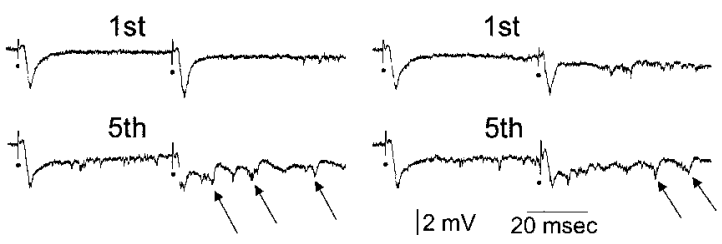

Figure 7. CA3 hyperexcitability is not antagonized by the NMDA receptor antagonist D-APV. $A$, Responses to a pair of hilar stimuli were recorded in stratum lucidum. Five pairs of stimuli were triggered at $1 \mathrm{~Hz}$. The responses to the first and the fifth pairs are shown. Abnormal activity is marked by the arrows, indicative of hyperexcitability. $B$, After a 15 min exposure to $50 \mu \mathrm{m}$ D-APV, the same stimuli shown in $A$ still produced hyperexcitability.

CA3b during hilar stimulation. As shown in Figure 6, simultaneous recordings in the cell layer and terminal zone of mossy fibers (stratum lucidum), demonstrated extracellularly recorded "field" EPSPs in stratum lucidum. This was true for the responses that occurred immediately after a single stimulus as well as those at longer latency, recruited by $1 \mathrm{~Hz}$ paired stimulation (Fig. 6). In all slices that were tested in this manner $(n=2$ proestrus; $n=3$ estrus), the maximal negativity (i.e., the maximum field EPSP) was always recorded from stratum lucidum. In other strata, such as stratum radiatum, the negative-going field potential was smaller in amplitude and mixed with positive potentials, indicating it was not likely to be generated by synapses in that lamina ( $n=5$ slices) (Fig. 6). These data suggested that hilar stimulation preferentially activated mossy fibers.

It has been reported that mossy fiber transmission is mediated primarily by AMPA receptors (for review, see Henze et al., 2000). Therefore, we used the NMDA receptor antagonist D-APV to further test the specificity of hilar stimuli for mossy fibers. As shown in Figure 7, there was no apparent effect of D-APV on hyperexcitability evoked by paired $1 \mathrm{~Hz}$ hilar stimulation of proestrous slices. Evoked responses were not diminished, and hyperexcitability was robust $30 \mathrm{~min}$ after exposure to $50 \mu \mathrm{M}$ D-APV $(n=3)$ (Fig. 7$)$. The same results were obtained using estrous slices $(n=3)$. These data are consistent with preferential mossy fiber activation. They also indicate that CA3 hyperexcitability is unlikely to be attributable to NMDA receptors, which is significant given that studies in area CA1 and in culture show that estradiol and BDNF facilitate NMDA receptor-mediated transmission (Woolley et al., 1997; Black, 1999; Murphy and Segal, 2001). The effects in CA3 may be different mechanistically, consistent with the APV resistance of area CA3 hyperexcitability after exposure of male rat slices to BDNF ( $n=15$; data not shown) (Scharfman et al., 1999).

Correlation between hormone levels and CA3 hyperexcitability. The preceding data suggested that estrogen release before ovulation might be responsible for the observed CA3 hyperexcitability at proestrus and estrus. Measurements of serum hormone levels confirmed cycle stage based on vaginal cytology patterns (Fig. 8). Furthermore, multiple regression analysis revealed a significant correlation in proestrous animals between the percentage of the slices from each animal that exhibited multiple population spikes in response to hilar stimulation and circulating estradiol levels (stepwise multiple regression analysis: standardized regression coefficient, $r=0.71$; ANOVA $F$-to-remove statistic for estradiol levels, $F=11.16$; df 1,$11 ; p=0.007)$. Neither progesterone nor testosterone levels contributed significantly to the power of the analysis in predicting multiple CA3 population spikes at proestrus (for progesterone levels: $F=2.06, p>0.1$; for testosterone levels: $F=$ $0.644, p>0.1)$. No significant correlations were observed between estradiol, progesterone, or testosterone levels and the electrophysiological data from CA3 at either estrus or metestrus.

Adding BDNF to slices of female rats increases CA3 excitability. Effects of exogenous BDNF were tested in slices that did not show hyperexcitability. Thus, in slices from metestrous rats $(n=5)$, the addition of $100 \mathrm{ng} / \mathrm{ml}$ BDNF to the perfusing buffer for over 30 min had a dramatic effect. As shown in Figure 9, paired hilar stimuli evoked multiple population spikes in area CA3 after BDNF exposure. Before BDNF exposure, these stimuli only evoked one population spike per stimulus. Schaffer collateral or fimbria stimulation evoked one population spike per stimulus before and after BDNF (data not shown). The same results were obtained when BDNF was applied to six of the slices from proestrous rats that demonstrated normal excitability (i.e., one population spike per stimulus). The same five pairs of $1 \mathrm{~Hz}$ stimuli that evoked one population spike per stimulus before BDNF was added evoked two or more population spikes per stimulus after a $30 \mathrm{~min}$ exposure to $100 \mathrm{ng} / \mathrm{ml}$ BDNF.

Inhibition of trkB normalizes CA3 hyperexcitability. To determine whether endogenous BDNF, acting at its high-affinity (trkB) receptor, might have contributed to the hyperexcitability observed on the morning of proestrus, we studied the effects of K252a, a potent inhibitor of receptor tyrosine kinases of the Trk family. As shown in Figure 10, bath application of K252a to slices from a proestrous rat eliminated the additional population spikes 


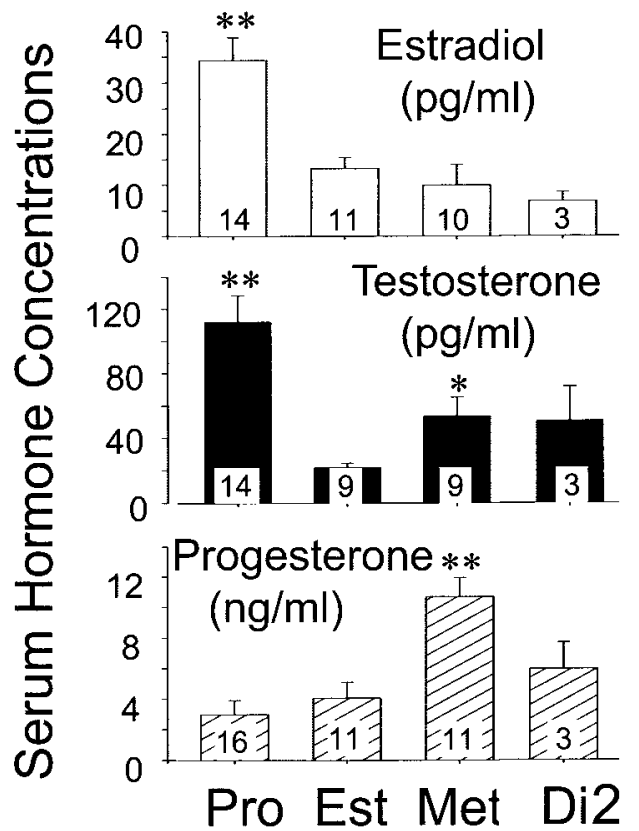

Figure 8. RIA analysis of reproductive hormones during the estrous cycle. Means $\pm S E M$ are shown for all cycle stages (Pro, proestrus; Est, estrus; Met, metestrus; Di2, diestrus 2), with the number of individual measurements indicated at the foot of each histogram bar. Significance of differences relative to hormone levels at estrus: ${ }^{*} p<0.05 ;{ }^{* *} p<0.01$ (Scheffe's test).
A. Metestrus

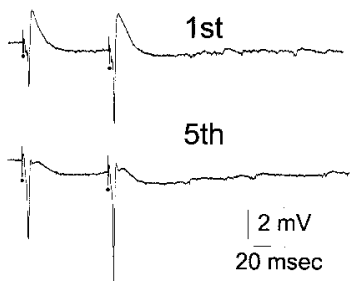

\section{B. Metestrus + BDNF}
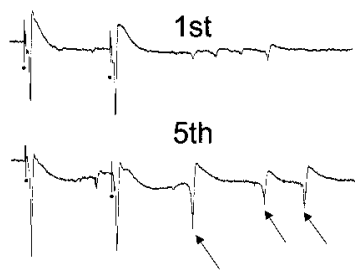

Figure 9. Effects of BDNF in area $C A 3$ of a slice from a metestrous rat. $A$, In a slice from an animal killed on the morning of metestrus, the first and fifth responses to consecutive pairs of hilar stimuli at $1 \mathrm{~Hz}$ are shown. Only one population spike was evoked per stimulus (normal excitability). $B$, The responses to the same stimuli shown in $A$ were triggered 60 min after adding BDNF (100 ng/ml) to the perfusing buffer. Multiple population spikes (arrows) were evoked in response to the fifth stimulus.

that were recruited by $1 \mathrm{~Hz}$ hilar stimulation $(n=2,500 \mathrm{nM} ; n=$ $3,1 \mu \mathrm{M})$. This effect required at least a $30 \mathrm{~min}$ incubation with K252a. K252a did not depress the first population spike that was evoked after each stimulus $(n=3)$ (Fig. 10), so there was no evidence of nonspecific depression of neuronal excitability. In other proestrous rats, $1 \mu \mathrm{M} \mathrm{K} 252 \mathrm{a}$ exposure for over $1 \mathrm{hr}$ did not depress the population spike evoked by a hilar stimulus $(n=2$; data not shown). The vehicle used to dissolve K252a (DMSO) did not have effects on the hilar-evoked population spike at the concentrations used ( $n=3 ; 0.05 \%)$, but slightly higher concentrations did increase the amplitude of the population spike $(n=3$, $0.08 \%$ ). Therefore, any effect of vehicle in these experiments was likely to counter the effect that was observed, rather than contribute to it.

A role of $\alpha 7$ nicotinic cholinergic receptors in CA3 hyperexcitability. At proestrus, the specific antagonist of $\alpha 7$ nicotinic cholinergic receptors ( $\alpha 7 \mathrm{nAChRs),} \mathrm{MLA,} \mathrm{blocked} \mathrm{multiple} \mathrm{popula-}$ tion spikes in area CA3 that were evoked by mossy fiber
A. Proestrus

B. Proestrus+ K252a
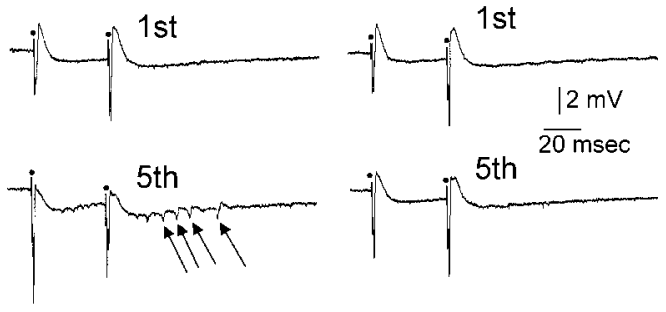

Figure 10. Pharmacological reversal of hyperexcitability in area CA3 by K252a. A, Responses recorded in the pyramidal cell layer of area CA3 to paired hilar stimuli are shown. Before bath application of K252a, multiple population spikes occurred after five paired stimuli at $1 \mathrm{~Hz}$ (arrows). $B$, After K252a perfusion for $60 \mathrm{~min}$, the same stimuli shown in $A$ only evoked one population spike per stimulus.
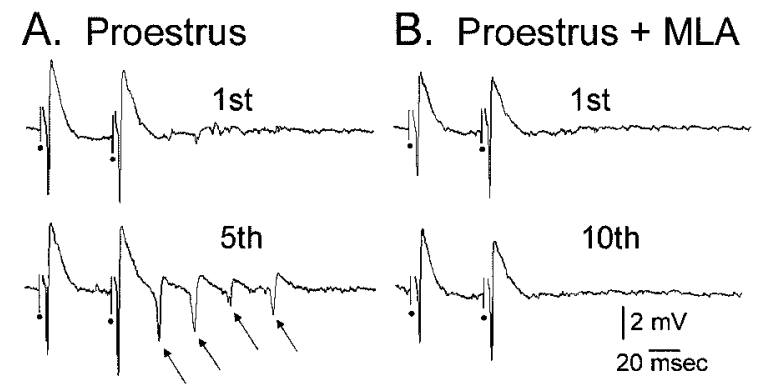

Figure 11. Pharmacological reversal of hyperexcitability in area CA3 by MLA. A, Responses recorded in the pyramidal cell layer of area CA3 in response to $1 \mathrm{~Hz}$ paired hilar stimuli are shown. Before bath application of MLA, multiple population spikes occurred after five paired stimuli at $1 \mathrm{~Hz}$ (arrows). B, After exposure to MLA for 20 min, the same stimuli shown in A only evoked one population spike per stimulus.

stimulation ( $50 \mathrm{nM}, n=5 ; 100 \mathrm{nM}, n=3$; slices from eight different rats) (Fig. 11). Thus, before MLA application, more than one population spike per stimulus was evoked after two to five pairs of mossy fiber stimuli at $1 \mathrm{~Hz}$. Then, MLA was added to the buffer perfusing the slices. Within 30 min after the addition of MLA, only one population spike per stimulus was evoked by the same stimuli, and this was true even if more than five pairs of stimuli were triggered (Fig. 11).

\section{Discussion}

\section{Summary}

The results of this study indicate that BDNF protein immunoreactivity in hippocampus varies across the estrous cycle, increasing at proestrus and estrus, particularly in the mossy fiber pathway. Concomitantly, patterns of evoked responses in CA1 and CA3 are altered in a manner resembling previously reported effects of adding recombinant BDNF to hippocampal slices from normal male rats (Kang and Schuman, 1995; Scharfman, 1997) or recordings from BDNF overexpressing mice (Croll et al., 1999). In area CA1, population spike amplitude was increased, and the input-output function became steeper, with an altered $\mathrm{ES}_{50}$ value at estrus. In area CA3, mossy fiber stimulation evoked multiple population spikes, particularly at estrus. These data suggest that the increase in hippocampal excitability normally observed in female rats during the periovulatory period may, at least in part, be a consequence of estrogen-mediated increases in BDNF synthesis. 


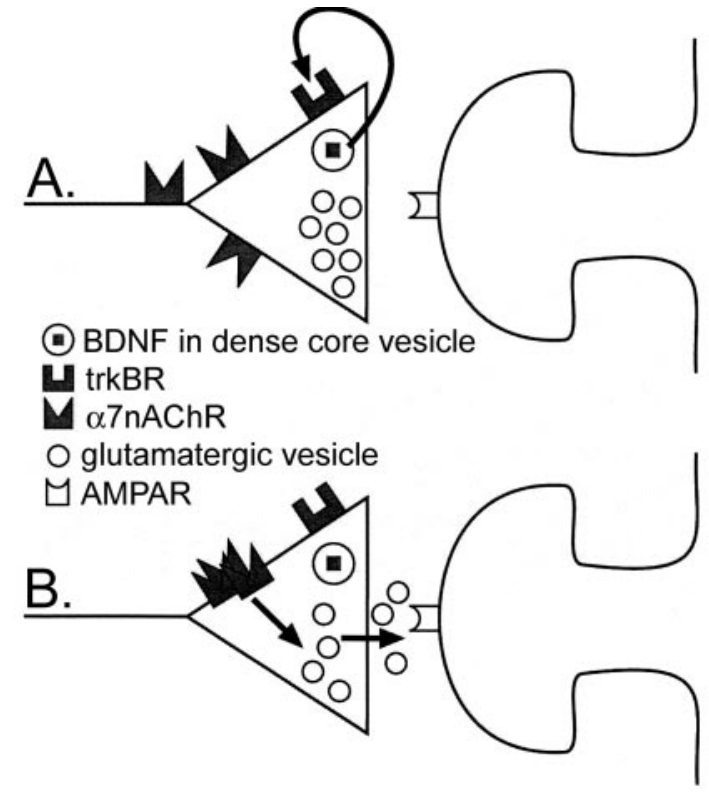

Figure 12. Hypothetical mechanism for hyperexcitability in area $\mathrm{CA} 3$ at periovulatory stages of the estrous cycle. $A$, It is hypothesized that trkB receptors (trkBR) and $\alpha 7 \mathrm{nAChRs}$ are present on mossy fiber terminals and that they modulate release of glutamate. AMPAR, AMPA receptor. $B$, At proestrus and estrus, the rise in estradiol triggers an increase in mossy fiber BDNF, so mossy fiber stimulation releases more BDNF and trkB receptor activation increases. TrkB receptors trigger a physical change in $\alpha 7 \mathrm{nAChRs}$, such as clustering of receptors, that in turn enhance $\alpha 7 \mathrm{nAChR}$ function. An increase in glutamate release occurs as a result. Additional considerations are elaborated in Discussion.

\section{BDNF expression}

The clearest distinctions in BDNF immunoreactivity were in the mossy fiber pathway, probably because it normally contains so much more BDNF than other hippocampal areas, and because axons are positioned side by side, with few non-BDNF afferents diluting the signal. However, increased BDNF also was evident, albeit to a lesser extent, in the neuropil of other areas, such as stratum radiatum of CA1 and CA3. This most likely corresponds to increased BDNF expression in CA1 and CA3 pyramidal cells and their axons, which normally contain BDNF mRNA (for review, see Gall, 1992) and sometimes showed somatic expression of BDNF (Fig. 2D). These data differ from those reported by Gibbs (1998, 1999), who showed that BDNF protein declined at proestrus and estrus despite increased BDNF mRNA. This may be because of methodological differences: we used immunocytochemistry whereas Gibbs $(1998,1999)$ chose BDNF ELISA, based on a different antibody from the one we used. It is possible that the different antibodies and procedures detect distinct pools of BDNF. An alternative explanation raised by Gibbs is also possible, namely that some BDNF protein is retrogradely transported out of the hippocampus at certain times of the cycle.

Why BDNF declines between estrus and metestrus is unclear at the present time. After experimental manipulations that induce BDNF, the expression of this peptide is elevated for at least $24 \mathrm{hr}$ (Reibel et al., 2000), which probably explains why BDNF immunoreactivity remains high between proestrus and estrus, although estrogen levels decline. Some time after the morning of estrus, the BDNF pool may become depleted or processed. The length of time required for this process to be completed may vary from one animal to another, and this could explain why BDNF immunoreactivity at metestrus remained high in a few cases. Prolonged elevation in BDNF may also explain why hyperexcitability was detected in area CA3 in slices from a few metestrous rats.
Interestingly, BDNF immunostaining in all intact female rats was greater than in adult males. To our knowledge, a gender difference in hippocampal BDNF expression has not been reported previously. The functional implications of this finding are not clear, because it is conceivable that the male compensates by upregulation of trkB receptors, or by other mechanisms such as testosterone modulation of BDNF (Louissaint et al., 2002).

\section{CA1 and CA3 excitability}

In both CA1 and CA3, increased excitability was noted at proestrus and estrus, compared with metestrous and ovariectomized rats. The maximum amplitude of the CA1 population spike increased at proestrus, concomitant to rising mean estrogen levels. Similarly, the incidence of CA3 hyperexcitability increased at proestrus, the rate of hyperexcitability being positively correlated with serum estradiol levels measured at the time of death. However, other factors than circulating estrogen could have contributed to the results, because the increase in both CA1 and CA3 excitability was even greater at estrus, when estrogen is low. There are two possible explanations for this. First, responses to estrogen may continue to develop for some time after the peak in circulating estrogen. Effects of estrogen in the brain typically last for a considerable period, well beyond the time when the hormone itself is cleared from the circulation (Clark et al., 1981; McEwen et al., 1990). Effects on BDNF immunoreactivity may peak at estrus because time is required for BDNF to be synthesized and transported anterogradely, or for BDNF to have effects on transmitter release, which can take $24 \mathrm{hr}$ (Tartaglia et al., 2001).

The second possibility is that the excitability observed at estrus may also reflect responses to progesterone, which peaks overnight between proestrus and estrus, falling back to baseline on the morning of estrus. It has been reported that abrupt reductions in progesterone lead to altered expression of the $\mathrm{GABA}_{\mathrm{A}}$ receptor subunit $\alpha 4$ (Smith et al., 1998), decreasing $\mathrm{GABA}_{\mathrm{A}}$ receptormediated inhibition and producing a syndrome termed "progesterone withdrawal." Progesterone withdrawal has been suggested to contribute to the enhanced susceptibility to convulsants (Moran and Smith, 1998; Frye and Bayon, 1999; Reddy et al., 2001). It could also contribute to the changes in CA1 and CA3 excitability observed at estrus. Indeed, changes resembling those in CA1 have been reported after cessation of progesterone administration (Hsu and Smith, 2003). It is important to note, however, that the nature of the change in CA3 excitability was similar at proestrus and estrus. Differences were not detected qualitatively or quantitatively. Thus, a very specific pattern of increased excitability (i.e., mossy fiber specificity, lack of spontaneous bursts, etc.) was apparent in CA3 on both days. This similarity, which to our knowledge has only been previously observed after BDNF exposure, suggests that the underlying mechanisms at proestrus and estrus, at least for CA3, may be similar. If so, estrogen-induced BDNF would be the most likely mediator, a view supported by the observation that CA3 hyperexcitability at proestrus was reversed by the trk receptor antagonist K252a. The K252a result does not exclude other trk receptors, however, such as trkA, which binds NGF but not BDNF. TrkA mRNA expression changes in the estrous cycle, although NGF mRNA does not (Gibbs, 1998). However, in the mossy fibers, it can be argued that most trk is trkB ( $\mathrm{He}$ et al., 2002). Furthermore, the fact that the addition of BDNF to metestrous slices reproduces the pattern of CA3 excitability observed at proestrus strongly suggests that BDNF is involved in the changes observed at proestrus.

An important question raised by the data are why effects in proestrus and estrous rats were not detected in all hippocampal 
slices. A likely factor in area CA3 is the choice of stimulus intensity and frequency, which were minimized to avoid spreading depression. In some slices that did not demonstrate abnormal evoked, stronger stimuli (i.e., greater than half-maximal) or more stimuli might have demonstrated hyperexcitability. Effects of testosterone may have contributed in some instances. As noted in the Results, one of the proestrous rats that had anomalously low CA3 excitability had elevated testosterone levels. Androgens antagonize some of the actions of estrogen (Teoh et al., 2000; Kipp and Ramirez, 2003), although acute application of testosterone to the hippocampus can increase excitability (Smith et al., 2002). Nevertheless, statistically, there was no indication that circulating testosterone levels were predictive of slice excitability: hyperexcitability was significantly correlated only with estrogen at proestrus. Moreover, in several instances, there was variation between slices from the same animal, when presumably the entire hippocampus was exposed to the same hormonal milieu before euthanasia. Such differences could be attributable to aspects of hormone or BDNF signaling that are labile in vitro. Consistent with this suggestion, only a subset of slices seem to respond when exposed to estrogen or BDNF (Wong and Moss, 1991; Carmignoto et al., 1997; Scharfman, 1997). It is also possible that slices varied in the preservation of recurrent excitatory circuitry, which would potentially influence hyperexcitability in area CA3 (Bains et al., 1999). If GABAergic interneurons are involved, which is suggested by studies of estrogen in hippocampus (Weiland, 1992; Murphy and Segal 2001; Velisek and Velisekova, 2002; Rudick et al., 2003), then preservation of interneurons may be critical.

\section{Possible mechanisms underlying hyperexcitability in area CA3 during periovulatory cycle stages}

Based solely on the data, it is likely that trk receptors and $\alpha 7 \mathrm{nAChRs}$ are key players. But how do these interact? Recent data provide potential insight: BDNF itself may alter $\alpha 7 \mathrm{nAChR}$ distribution, enhancing $\alpha 7$ function (Kawai et al., 2002). Given the evidence that BDNF and $\alpha 7 \mathrm{nACh}$ receptors influence transmitter release (Girod et al., 2000; Tyler et al., 2002), increased glutamate release would be a likely consequence. Our hypothesis is diagrammed in Figure 12. In this diagram, trkB receptors and $\alpha 7 \mathrm{nAChRs}$ are located on mossy fiber boutons (Gray et al., 1996; He et al., 2002), although there also are other possibilities (Drake et al., 1999; Vogt and Regehr, 2001), and indeed the effects of BDNF on $\alpha 7 \mathrm{nACh}$ receptors have thus far been shown only in other neurons (Kawai et al., 2002). We hypothesize that estrogeninduced elevation in BDNF at proestrus leads to greater BDNF release upon stimulation of mossy fibers, increased $\alpha 7 \mathrm{nAChR}$ function, and increased glutamate release from mossy fibers.

Why would this lead to hyperexcitability? Excess glutamate may accumulate extrasynaptically, particularly on repetitive stimulation, and the normal inhibitory mechanisms that are present may be insufficient to control the effects of increased extracellular glutamate on pyramidal cells. Additional effects of BDNF and estradiol, such decreased GABAergic transmission (Tanaka et al., 1997; Murphy and Segal, 2001; Rudick and Woolley, 2001), could be key.

\section{Significance}

These results are consistent with the hypothesis that hyperexcitability induced by estrogen may contribute to the induction of seizures in hippocampus in the periovulatory phase of the female reproductive cycle (Herzog, 1991; Morrell, 1999). Furthermore, the data suggest that a possible mechanism by which estrogen increases seizure susceptibility is via induction of hippocampal
BDNF expression. The relevance of hippocampal BDNF to epilepsy will require additional clarification, because some experimental paradigms do not show proconvulsant effects of either BDNF or estrogen (Larmet et al., 1995; Velisek et al., 1999; Woolley, 2000). Nevertheless, the strong induction of BDNF immunoreactivity in hippocampus at proestrus and estrus, the increased evoked activity observed on stimulation of the pathways containing increased BDNF, and the similarity between the recordings from slices with high endogenous BDNF expression and metestrous slices exposed to BDNF, all point to a potential role for BDNF. Additional study of the role of BDNF-induced hyperexcitability could provide an improved understanding of the mechanisms underlying estrogen-mediated enhancement of seizure susceptibility, while potentially providing new avenues for the development of treatments for hormone-sensitive epilepsy.

\section{References}

Bäckström T (1976) Epileptic seizures in women related to plasma estrogen and progesterone during the menstrual cycle. Acta Neurol Scand 54:321-347.

Bains JS, Longacher JM, Staley KJ (1999) Reciprocal interactions between CA3 network activity and strength of recurrent collateral synapses. Nat Neurosci 2:720-726.

Belelli D, Bolger MB, Gee KW (1989) Anticonvulsant profile of the progesterone metabolite 5 $\alpha$-pregnan-3 $\alpha$-ol-20-one. Eur J Pharmacol 166:325-329.

Berchtold NC, Kesslak JP, Pike CJ, Adlard PA, Cotman CW (2001) Estrogen and exercise interact to regulate brain-derived neurotrophic factor mRNA and protein in expression in the hippocampus. Eur J Neurosci 14:1992-2002.

Black IB (1999) Trophic regulation of synaptic plasticity. J Neurobiol 4:108-118.

Carmignoto G, Pizzorusso T, Tia S, Vicini S (1997) Brain-derived neurotrophic factor and nerve growth factor potentiate excitatory synaptic transmission in the rat visual cortex. J Physiol (Lond) 498:153-164.

Claiborne BJ, Xiang Z, Brown TH (1993) Hippocampal circuitry complicates analysis of long-term potentiation in mossy fiber synapses. Hippocampus 3:115-121.

Clark CR, MacLusky NJ, Parsons B, Naftolin F (1981) Effects of estrogen deprivation on brain estrogen and progestin receptor levels and the activation of female sexual behavior. Horm Behav 15:289-298.

Conner JM, Lauterborn JC, Yan Q, Gall CM, Varon S (1997) Distribution of brain-derived neurotrophic factor (BDNF) protein and mRNA in the normal adult rat CNS: evidence for anterograde axonal transport. J Neurosci 17:2295-2313.

Croll SD, Suri C, Compton DL, Simmons MV, Yancopoulos GD, Lindsay RM, Wiegand SJ, Rudge JS, Scharfman HE (1999) Brain-derived neurotrophic factor transgenic mice exhibit passive avoidance deficits, increased seizure severity and in vitro hyperexcitability in the hippocampus and entorhinal cortex. Neuroscience 93:1491-1506.

Danzer SC, Crooks KR, Lo DC, McNamara JO (2002) Increased expression of brain-derived neurotrophic factor induces formation of basal dendrites and axonal branching in dentate granule cells in hippocampal explant cultures. J Neurosci 22:9754-9763.

Drake CT, Milner TA, Patterson SL (1999) Ultrastructural localization of full-length trkB immunoreactivity in rat hippocampus suggests multiple roles in modulating activity-dependent synaptic plasticity. J Neurosci 19:8009-8026.

DeLean A, Munson PJ, Rodbard D (1978) Simultaneous analysis of families of sigmoidal curves: application to bioassay, radioligand assay and physiological dose- response curves. Am J Physiol 235:E97-E102.

Edwards HE, Burnham WM, Mendonca A, Bowlby DA, MacLusky NJ (1999) Steroid hormones affect limbic afterdischarge thresholds and kindling rates in adult female rats. Brain Res 838:136-150.

Edwards HE, Mo V, Burnham WM, MacLusky NJ (2001) Gonadectomy unmasks an inhibitory effect of progesterone on amygdala kindling in male rats. Brain Res 889:260-263.

Foy MR, Xu J, Xie X, Brinton RD, Thompson RF, Berger TW (1999) $17 \beta$ estradiol enhances NMDA receptor-mediated EPSPs and long-term potentiation. J Neurophysiol 81:925-929. 
Frye CA, Bayon LE (1999) Cyclic withdrawal from endogenous and exogenous progesterone increases kainic acid and perforant pathway induced seizures. Pharmacol Biochem Behav 62:315-321.

Frye CA, Scalise TJ (2000) Anti-seizure effects of progesterone and $3 \alpha, 5 \alpha$ THP in kainic acid and perforant pathways models of epilepsy. Psychoneuroendocrinology 25:407-420.

Frye CA, Rhodes ME, Walf A, Harney J (2002) Progesterone reduces pentylenetetrazol-induced ictal activity of wild-type mice but not those deficient in type I $5 \alpha$-reductase. Epilepsia 43:14-17.

Gall CM (1992) Regulation of brain neurotrophin expression by physiological activity. Trends Pharmacol Sci 13:401-403.

Gibbs RB (1998) Levels of trkA and BDNF mRNA, but not NGF mRNA, fluctuate across the estrous cycle and increase in response to acute hormone replacement. Brain Res 787:259-268.

Gibbs RB (1999) Treatment with estrogen and progesterone affects relative levels of brain-derived neurotrophic factor mRNA and protein in different regions of the adult rat brain. Brain Res 844:20-27.

Girod R, Barazangi N, McGehee D, Role LW (2000) Facilitation of glutamatergic neurotransmission by presynaptic nicotinic acetylcholine receptors. Neuropharmacology. 39:2715-2725.

Gray R, Rajan AS, Radcliffe KA, Yakehiro M, Dani JA (1996) Hippocampal synaptic transmission enhanced by low concentrations of nicotine. Nature 383:670-671.

He XP, Minichiello L, Klein R, McNamara JO (2002) Immunohistochemical evidence of seizure-induced activation of trkB receptors in the mossy fiber pathway of adult mouse hippocampus. J Neurosci 22:7502-7508.

Henze DA, Urban NN, Barrionuevo G (2000) The multifarious hippocampal mossy fiber pathway: a review. Neuroscience 98:407-427.

Herzog AG (1991) Reproductive endocrine considerations and hormonal therapy for women with epilepsy. Epilepsia 32 [Suppl 6]:S27-S33.

Herzog AG, Klein P, Ransil BJ (1997) Three patterns of catamenial epilepsy. Epilepsia 38:1082-1088.

Hsu FC, Smith SS (2003) Progesterone withdrawal reduces paired-pulse inhibition in rat hippocampus: dependence on $\mathrm{GABA}_{\mathrm{A}}$ receptor $\alpha 4$ subunit upregulation. J Neurophysiol 89:186-198.

Kang H, Schuman EM (1995) Long-lasting neurotrophin-induced enhancement of synaptic transmission in the adult hippocampus. Science 267:1658-1662.

Kawai H, Zago W, Berg DK (2002) Nicotinic $\alpha 7$ receptor clusters on hippocampal GABAergic neurons: regulation by synaptic activity and neurotrophins. J Neurosci 22:7903-7912.

Kipp JL, Ramirez VD (2003) Estradiol and testosterone have opposite effects on microtubule polymerization. Neuroendocrinology 77:258-272.

Larmet Y, Reibel S, Carnahan J, Nawa H, Marescaux C, Depaulis A (1995) Protective effects of brain-derived neurotrophic factor on the development of hippocampal kindling in the rat. NeuroReport 6:1937-1941.

Liu Y, Fowler CD, Young LJ, Yan Q, Insel TR, Wang Z (2001) Expression and estrogen regulation of brain-derived neurotrophic factor gene and protein in the forebrain of female prairie voles. J Comp Neurol 33:499-514.

Louissaint A, Rao S, Leventhal C, Goldman SA (2002) Coordinated interaction of neurogenesis and angiogenesis in the adult songbird brain. Neuron 34:945-960.

Lu B, Gottschalk W (2000) Modulation of hippocampal synaptic transmission and plasticity by neurotrophins. Prog Brain Res 128:231-241.

McEwen BS, Coirini EH, Schumacher M (1990) Steroid effects on neuronal activity: when is the genome involved? Ciba Found Symp 153:3-12.

Moran MH, Smith S (1998) Progesterone withdrawal I: pro-convulsant effects. Brain Res 807:84-90.

Morrell MJ (1999) Epilepsy in women: the science of why it is special. Neurology 53 [Suppl 1]:S42-S8. .

Murphy DD, Segal M (2001) Estradiol induces formation of dendritic spines in hippocampal neurons: functional correlates. Horm Behav 40:156-159.

Pan Y, Anthony M, Clarkson TB (1999) Evidence for up-regulation of brain-derived neurotrophic factor mRNA by soy phytoestrogens in the frontal cortex of retired breeder female rats. Neurosci Lett 61:17-20.

Paxinos G, Watson C (1986) The rat brain in stereotaxic coordinates, Ed 2. New York: Academic.

Rage F, Givalois L, Marmigere F, Tapia-Arancibia L, Arancibia S (2002) Immobilization stress rapidly modulates BDNF mRNA expression in the hypothalamus of adult male rats. Neuroscience 112:309-318.
Reddy DS, Kim HY, Rogawski MA (2001) Neurosteroid withdrawal model of perimenstrual catamenial epilepsy. Epilepsia 42:328-336.

Reibel S, Vivien-Roels B, Le BT, Larmet Y, Carnahan J, Marescaux C, Depaulis A (2000) Overexpression of neuropeptide Y induced by brainderived neurotrophic factor in the rat hippocampus is long lasting. Eur J Neurosci 12:595-605.

Rogawski M (2003) Progesterone, neurosteroids, and the hormonal basis of catamenial epilepsy. Ann Neurol 53:288-291.

Rudick CN, Woolley CS (2001) Estrogen regulates functional inhibition of hippocampal CA1 pyramidal cells in the adult female rat. J Neurosci 21:6532-6543

Rudick CN, Gibbs RB, Woolley CS (2003) A role for the basal forebrain cholinergic system in estrogen-induced disinhibition of hippocampal pyramidal cells. J Neurosci 23:4479-4490.

Schaaf MJ, deJong J, deKloet ER, Vreugdenhil E (1998) Downregulation of BDNF mRNA and protein in the rat hippocampus by corticosterone. Brain Res 813:112-120.

Scharfman HE (1997) Hyperexcitability in combined entorhinal/hippocampal slices of adult rat after exposure to brain-derived neurotrophic factor. J Neurophysiol 78:1082-1095.

Scharfman HE, Goodman JH, Sollas AL (1999) Actions of brain-derived neurotrophic factor in slices from rats with spontaneous seizures and mossy fiber sprouting in the dentate gyrus. J Neurosci 19:5619-5631.

Scharfman HE, Smith KL, Goodman JH, Sollas AL (2001) Survival of dentate hilar mossy cells after pilocarpine-induced seizures and their synchronized burst discharges with area CA3 pyramidal cells. Neuroscience 104:741-759.

Schuman EM (1999) Neurotrophin regulation of synaptic transmission. Curr Opin Neurobiol 9:105-109.

Sharrow KM, Kumar A, Foster TC (2002) Calcineurin as a potential contributor in estradiol regulation of hippocampal synaptic function. Neuroscience 13:89-97.

Sherwood NM (1977) Estrous cycles after electrical stimulation of the brain in conscious rats: effect of current strength, estradiol benzoate and progesterone. Endocrinology 100:18-29.

Singh M, Meyer EM, Simpkins JW (1995) The effect of ovariectomy and estradiol replacement on brain-derived neurotrophic factor messenger ribonucleic acid expression in cortical and hippocampal brain regions of female Sprague-Dawley rats. Endocrinology 136:2320-2324.

Smith MD, Sargent-Jones L, Wilson MA (2002) Sex differences in hippocampal slice excitability: role of testosterone. Neuroscience 109:517-530.

Smith S, Gong QH, Hsu FC, Markowitz RS, ffrench-Mullen JM, Li X (1998) $\mathrm{GABA}_{\mathrm{A}}$ receptor $\alpha 4$ subunit suppression prevents withdrawal properties of an endogenous steroid. Nature 92:926-930.

Sohrabji F, Miranda RC, Toran-Allerand CD (1995) Identification of a putative estrogen response element in the gene encoding brain-derived neurotrophic factor. Proc Natl Acad Sci USA 92:11110-11114.

Solum DT, Handa RJ (2002) Estrogen regulates the development of brainderived neurotrophic factor mRNA and protein in the rat hippocampus. J Neurosci 22:2650-2659.

Tan M, Tan U (2001) Sex difference in susceptibility to epileptic seizures in rats: importance of estrous cycle. Int J Neurosci 108:175-191.

Tanaka T, Saito H, Matsuki N (1997) Inhibition of GABA $A_{A}$ synaptic responses by brain-derived neurotrophic factor (BDNF) in rat hippocampus. J Neurosci 17:2959-2966.

Tartaglia N, Du J, Tyler WJ, Neale E, Pozzo-Miller L, Lu B (2001) Protein synthesis-dependent and -independent regulation of hippocampal synapses by brain-derived neurotrophic factor. J Biol Chem 276:37585-37593.

Tauboll E, Lindstrom S (1993) The effect of progesterone and its metabolite $5 \alpha$-pregnan-3 $\alpha$-ol-20-one on focal epileptic seizures in the cat's visual cortex in vivo. Epilepsy Res 14:17-30.

Teoh H, Quan A, Leung SW, Man RY (2000) Differential effects of $17 \beta$ estradiol and testosterone on the contractile responses of porcine coronary arteries. Br J Pharmacol 129:1301-1308.

Turner CD, Bagnara JT (1971) General endocrinology, Ed 5. Philadelphia: Saunders.

Tyler WJ, Perrett SP, Pozzo-Miller LD (2002) The role of neurotrophins in neurotransmitter release. The Neuroscientist 8:524-531.

Velisek L, Veliskova J (2002) Estrogen treatment protects $\mathrm{GABA}_{\mathrm{B}}$ inhibition in the dentate gyrus of female rats after kainic acid-induced status epilepticus. Epilepsia 43 [Suppl 5]:146-151.

Velisek L, Veliskova J, Etgen AM, Stanton PK, Moshe SL (1999) Region- 
specific modulation of limbic seizure susceptibility by ovarian steroids. Brain Res 842:132-138.

Vogt KE, Regehr WG (2001) Cholinergic modulation of excitatory synaptic transmission in the CA3 area of the hippocampus. J Neurosci 21:75-83.

Weiland NG (1992) Glutamic acid decarboxylase messenger ribonucleic acid is regulated by estradiol and progesterone in the hippocampus. Endocrinology 131:2697-2702.

Wilson MA (1992) Influences of gender, gonadectomy, and estrous cycle on $\mathrm{GABA} / \mathrm{BZ}$ receptors and benzodiazepine responses in rats. Brain Res Bull 29:165-172.

Wong M, Moss RL (1991) Electrophysiological evidence for a rapid membrane action of the gonadal steroid, $17 \beta$-estradiol, on CA1 pyramidal neurons of the rat hippocampus. Brain Res 543:148-152.
Woolley CS (2000) Estradiol facilitates kainic acid-induced, but not flurothyl-induced, behavioral seizure activity in adult female rats. Epilepsia 41:510-515.

Woolley CS, Schwartzkroin PA (1998) Hormonal effects on the brain. Epilepsia 39 [Suppl 8]:S2-S8.

Woolley CS, Weiland NG, McEwen BS, Schwartzkroin PA (1997) Estradiol increases the sensitivity of hippocampal CA1 pyramidal cells to NMDA receptor-mediated synaptic input: correlation with dendritic spine density. J Neurosci 17:1848-1859.

Yan Q, Rosenfeld RD, Matheson CR, Hawkins N, Lopez OT, Bennett L, Welcher AA (1997) Expression of brain-derived neurotrophic factor protein in the adult rat central nervous system. Neuroscience 78:431448. 